\title{
Correction to: Protective Effects of Tyrosol Against DSS-Induced Ulcerative Colitis in Rats
}

\author{
Mehmet Güvenç $\mathbb{D}^{1,7}$ Mustafa Cellat, ${ }^{1}$ Hüseyin Özkan, ${ }^{2}$ İbrahim Ozan Tekeli, ${ }^{3}$ Ahmet Uyar, \\ İshak Gökçek, ${ }^{1}$ Cafer Tayer İșler, ${ }^{5}$ and Akın Yakan ${ }^{6}$
}

\author{
Correction to: Inflammation (2019) \\ https://doi.org/10.1007/s10753-019-01028-8
}

The below Funding Information is missing in the original article.

\section{FUNDING INFORMATION}

This work was supported by the Hatay Mustafa Kemal University Scientific Research Projects Coordination Unit project number of 18.M.013.

Publisher's Note Springer Nature remains neutral with regard to jurisdictional claims in published maps and institutional affiliations.

The online version of the original article can be found at https://doi.org/ 10.1007/s10753-019-01028-8

\footnotetext{
${ }^{1}$ Faculty of Veterinary Medicine, Department of Physiology, Hatay Mustafa Kemal University, Hatay, Turkey

${ }^{2}$ Faculty of Veterinary Medicine, Department of Genetics, Hatay Mustafa Kemal University, Hatay, Turkey

${ }^{3}$ Faculty of Veterinary Medicine, Department of Pharmacology and Toxicology, Hatay Mustafa Kemal University, Hatay, Turkey

${ }^{4}$ Faculty of Veterinary Medicine, Department of Pathology, Hatay Mustafa Kemal University, Hatay, Turkey

${ }^{5}$ Faculty of Veterinary Medicine, Department of Surgery, Hatay Mustafa Kemal University, Hatay, Turkey

${ }^{6}$ Faculty of Veterinary Medicine, Department of Zootechnics, Erciyes University, Kayseri, Turkey

${ }^{7}$ To whom correspondence should be addressed at Faculty of Veterinary Medicine, Department of Physiology, Hatay Mustafa Kemal University, Hatay, Turkey. E-mail: mguvenc@mku.edu.tr
} 